\title{
DynamicSainT
}

Jilid. IV No. 2., Oktober 2019

\section{PENGARUH PENGGUNAAN BATU LATERIT SEBAGAI ALTERNATIF PENGGANTI AGREGAT KASAR PADA KEKUATAN BETON}

\author{
Mohamad Isram M. Ain ${ }^{1 *}$, Ali Arifin Soeparlan ${ }^{2}$ \\ ${ }^{1}$ Politeknik Negeri Balikpapan \\ ${ }^{2}$ Politeknik Negeri Balikpapan \\ *mohamad.isram@poltekba.ac.id
}

\begin{abstract}
ABSTRAK
Pembangunan infrasrtuktur seperti perumahan, perkantoran, rumah sakit dan jembatan di Balikpapan tidak terlepas dari penggunaan beton. Ketersediaan bahan pembentuk beton di Balikpapan masih mengandalkan bahan baku yang berasal dari luar daerah, terutama agregat halus dan agregat kasar yang harus didatangkan dari daerah Palu. Berdasarkan permasalahan tersebut, maka perlu dicari langkah-langkah penyelesaian untuk mengatasi kendala tersebut,salah satunya dengan memaksimalkan penggunaan batu laterit yang diharapkan dapat menjadi alternatif pengganti parsial agregat kasar. Metode yang dilakukan pada penelitian ini adalah dengan melakukan pengujian terhadap kuat tekan beton dengan variasi campuran batu laterit terhadap kerikil Palu dengan variasi campuran 10\%, 20\%, 30\%, 40\% dan $50 \%$ yang diuji kekuatannya pada umur 28 hari. Hasil penelitian menunjukkan kuat tekan optimum diperoleh pada variasi campuran $10 \%$ batu laterit yaitu sebesar 25,1 MPa nilai ini mendekati kuat tekan beton normal yang menggunakan 100\% kerikil Palu yaitu sebesarv25,8 MPa dan kuat tekan terendah yaitu pada variasi campuran 50\% batu laterit yaitu sebesar 8,9 MPa.
\end{abstract}

Kata Kunci: kuat tekan, agregat kasar alternatif, batu laterit

\section{PENDAHULUAN}

Balikpapan merupakan salah satu kota di Indonesia yang sedang giat melakukan pembangunan diberbagai bidang salah satunya adalah pembangunan dibidang infrastrukutur. Pembangunan dibidang infrstruktur semakin menggeliat seiring dengan rencana dari pemerintah pusat memindahkan ibu kota negara ke Kalimantan Timur. Pembangunan infrasrtuktur seperti perumahan, perkantoran, rumah sakit dan jembatan tidak terlepas dari penggunaan beton.

Beton didapat dari hasil pencampuran agregat halus pasir dan agregat kasar yaitu batu pecah atau bahan semacam lainnya dengan menambahkan bahan perekat semen secukupnya dan air sebagai bahan pembantu guna keperluan reaksi kimia selama proses pengerasan dan perawatan beton berlangsung, serta dapat pula diberi bahan tambahan lainnya yang dapat berfungsi untuk memperkuat atau mempercepat perkembangan kekuatan beton tersebut. Agregat mempunyai pengaruh besar terhadap perilaku beton ketika mengeras. Oleh karena itu ketersediaan agregat menjadi sangat vital.

Ketersediaan bahan pembentuk beton di Balikpapan masih mengandalkan bahan baku yang berasal dari luar daerah, terutama agregat halus dan agregat kasar yang harus didatangkan dari daerah Palu. Berdasarkan permasalaan tersebut maka perlu dicari langkah-langkah penyelesaian untuk mengatasi permasalahan tersebut, salah satunya adalah dengan memaksimalkan potensi batu laterit sebagai salah satu sumber daya alam yang cukup potensial untuk diteliti.

Batu laterit yang digunakan dalam penelitian ini berasal dari daerah Batakan, Kelurahan Manggar, Kecamatan Balikpapan 


\section{DynamicSainT}

Jilid. IV No. 2., Oktober 2019

Timur, Balikpapan, Kalimantan Timur. Didaerah tersebut terdapat potensi batu laterit yang melimpah namun belum dimanfaatkan dengan maksimal untuk pembangunan infrastruktur. Oleh karena itu timbul pemikiran untuk memanfaatkan batu laterit tersebut sebagai pengganti parsial agregat kasar pada campuran beton.

\section{KAJIAN PUSTAKA}

Beton merupakan campuran semen Portland atau semen hidraulik yang lain, agregat kasar, agregat halus, air maupun dengan penambahan zat tambahan lain yang menyatu dalam wujud padat. Beton seperti yang dikenal sekarang ini, adalah suatu bahan bangunan dan konstruksi, yang sifat-sifatnya dapat ditentukan lebih dahulu dengan mengadakan perencanaan dan teliti terhadap bahan- bahan yang dipilih. Agregat adalah butiran mineral alami yang berfungsi sebagai bahan pengisi dalam campuran mortar atau beton (Tjokrodimulyo, 1992). Agregat menempati 70-75 \% dari total volume beton maka kualitas agregat sangat berpengaruh terhadap kualitas beton. Walaupun fungsinya hanya sebagai pengisi, agregat memiliki kontribusi positif pada sifat beton, seperti stabilitas volume, ketahanan abrasi, dan ketahanan umum (durability). Bahkan sifat fisik beton secara langsung tergantung pada sifat agregat, seperti kepadatan, panas jenis, dan modulus elastisitas (Antoni dan Nugraha, 2004). Secara umum, agregat menjadi agregat kasar dan agregat halus. Agregat kasar biasa juga disebut kerikil sebagai hasil desintegrasi alami dari batuan atau berupa batu pecah yang diperoleh dari industri pemecah batu, dengan butirannya berukuran antara $4,76 \mathrm{~mm}-150$ $\mathrm{mm}$ dan Agregat halus untuk beton dapat berupa pasir alam sebagai hasil desintegrasi alami dari batuan-batuan atau berupa pasir buatan yang dihasilkan oleh alat pemecah batu. Agregat ini berukuran 0,063 mm - 4,76 $\mathrm{mm}$ yang meliputi pasir kasar (coarse sand) dan pasir halus (fine sand).
Batu laterit adalah tanah yang mengeras menyerupai batu dari hasil pengendapan zat-zat seperti nikel dan besi. Laterit sendiri terbentuk secara alami yang didalamnya banyak terkandung unsur dan zatzat hara yang membentuk lapisan tanah tersebut mengeras seperti batu. Laterit banyak ditemui diwilayah beriklim tropis yang panas dan lembab. akibat dari kandungan oksida besi dan nikel yang begitu banyak sehingga menjadikan tanah laterit mengeras menyerupai batu. Komposisi mineral dan kimia di dalam batu laterit sangat berpengaruh pada batuan induknya, laterit umumnya mengandung sejumlah besar kwarsa dan oksida titanium, zirkon, besi, timah, mangan dan alumunium, yang tertinggal dari dari proses pengausan. Dahulu kala batu laterit sering dimanfaatkan sebagai bahan pembuatan bata karena ketika lembab laterit mudah dipotong, namun setelah terkena udara dalam waktu yang lama akan mengeras seperti batu. Menurut Yves Tardy, peneliti dari French Institut National Polytechnique De Toulouse And The Centre National De La Recherche Scientifique, memperkirakan bahwa jenis laterit menutupi sekitar sepertiga dari seluruh daratan di dunia. Lapisan ini adalah sublapisan dari hutan-hutan di khatulistiwa, sabana-sabana di wilayah tropis yang lembab. Negara-negara yang kaya akan jenis laterit adalah Brazil, Australia, Guatemala, Kolombia, Eropa Tengah, Myanmar, Kuba, Indonesia dan Filipina. Beberapa penemuan geografis menunjukan bahwa deretan batu laterit banyak digunakan sebagai pondasi kuil-kuil di Kamboja pada abad ke-9 dan ke-12. Indonesia adalah salah satu penghasil laterit terbesar di dunia dengan total $1,063,843,000$ ton dari hasil pemetaan tahun 2004 dimana 50\% terdapat di Pulau Kalimantan. Diprediksi hampir $70 \%$ jenis Batu Laterit yang ada di Kalimantan adalah yang kualitas baik dan dapat dimanfaatkan untuk bahan-bahan pembuatan elemen konstruksi 


\section{DynamicSainT}

Jilid. IV No. 2., Oktober 2019

\section{METODOLOGI}

Penelitian ini menggunakan metode eksperimen, yaitu penelitian dengan percobaan langsung di laboratorium yang bertujuan untuk menyelidiki hubungan sebab akibat antara satu sama lain dan membandingkan hasilnya. Penelitian ini dilakukan dengan tujuh tahapan yang diawali dengan studi pustaka untuk mempelajari jurnal-jurnal penelitian, prosiding dan bukubuku referensi yang berhubungan dengan penelitian ini.

Tahap kedua adalah pemeriksaan agregat untuk mengetahui sifat-sifat fisik dari agregat yang akan digunakan

Tahap selanjutnya adalah mix design dengan melakukan rancangan campuran beton yang dilaksanakan di laboratorium uji bahan Politeknik Negeri Balikpapan. Rancangan campuran beton yang digunakan adalah :

Tabel 1 . Bahan susun beton

\begin{tabular}{cc}
\hline Bahan & Berat $/ \mathrm{m}^{3}$ \\
\hline Semen & $324.56 \mathrm{~kg}$ \\
Pasir Palu & $496.55 \mathrm{~kg}$ \\
Kerikil Palu & $1496.24 \mathrm{~kg}$ \\
Air & 185 liter \\
\hline
\end{tabular}

Tahap keempat yaitu pembuatan benda uji dengan variasi penggunaan agregat kasar kerikil Palu yang dikombinasikan dengan batu laterit, dengan kode variasi BN, LT1, LT2, LT3, LT4, dan LT5, yang pada masingmasing variasi dilakukan lima kali pengecoran, dengan perincian sebagai berikut:

Tabel 2 . Variasi Kerikil Palu dan Batu Laterit

\begin{tabular}{cccccc}
\hline \multirow{2}{*}{ NO } & \multirow{2}{*}{ Vrs } & $\begin{array}{r}\text { Berat } \\
(\mathrm{kg})\end{array}$ & $\begin{array}{r}\text { Prsnts } \\
(\%)\end{array}$ & $\begin{array}{c}\text { Berat } \\
(\mathrm{kg})\end{array}$ & $\begin{array}{c}\text { Prsnts } \\
(\%)\end{array}$ \\
\hline 1 & BN & 1496,24 & 100 & - & 0 \\
2 & LT1 & 1346,62 & 90 & 149,62 & 10 \\
3 & LT2 & 1197 & 80 & 299,24 & 20 \\
4 & LT3 & 1047,38 & 70 & 448,86 & 30 \\
5 & LT4 & 897,76 & 60 & 598,48 & 40 \\
6 & LT5 & 748,12 & 50 & 748,12 & 50 \\
\hline
\end{tabular}

Tahap kelima yaitu uji slump untuk mengetahui nilai kelecekan dari campuran beton yang direncanakan

Tahap keenam adalah perawatan beton selama 28 hari dengan menggunakan metode perendaman (curring).

Tahap selanjutnya adalah pengujian kuat tekan benda uji. Pemeriksaan kuat tekan dilakukan untuk menentukan kuat tekan beton dengan cara menghitung beban persatuan luas yang menyebabkan beton hancur

Hasil pengujian yang diharapkan berupa kuat tekan yang paling optimal dari variasi campuran agregat kasar, yang kemudian akan dibandingkan dengan beton yang menggunakan 100\% kerikil Palu sebagai agregat kasar kemudian diambil kesimpulan akhir.

\section{Rumusan Masalah}

Mengetahui pengaruh penggantian sebagian kerikil Palu dengan batu laterit

terhadap kualitas campuran beton yang dihasilkan. Mengetahui nilai kuat tekan optimal beton yang dihasilkan pada setiap variasi penggantian batu laterit.

\section{Tujuan Penelitian}

Tujuan dari penelitian ini adalah sebagai berikut. (1) Memaksimalkan pemanfaatan batu laterit untuk pembuatan beton terutama bagi bagi masyarakat Balikpapan. (2) harapan agar batu laterit dapat menjadi alternatif pengganti parsial kerikil Palu yang biasa digunakan oleh masyarakat Balikpapan untuk pembuatan beton.

\section{HASIL DAN PEMBAHASAN}

\subsection{Sifat Fisik Agregat}

Beton sebagian besar volumenya terdiri dari agregat kasar dan agregat halus. Karena kualitas atau mutu dari beton sangat dipengaruhi oleh kualitas material yang digunakan, maka perlu sekali diadakan pemeriksaan atau pengujian material di 


\section{DynamicSainT}

Jilid. IV No. 2., Oktober 2019

laboratorium. Agar material yang digunakan sesuai dengan persyaratan yang ditentukan sehingga beton yang dihasilkan akan awet, kuat, dan ekonomis.

\subsection{Pemeriksaan Agregat Halus}

Dari pemeriksaan modulus halus butir (MHB) pasir Palu diperoleh nilai nilai MHB yaitu sebesar 2,49. Hasil ini memenuhi syarat karena berada dalam nilai MHB pasir yaitu 1,5 - 3,8. Berdasarkan SNI 03-2816-1992 kadar lumpur agregat halus normal yang diijinkan adalah maksimal 5\%. Dari hasil pengujian kadar lumpur pada pasir Palu diperoleh kadar lumpur yang terkandung sebesar 1,64\% ini menunjukkan bahwa kadar lumpur yang terkandung masih dalam batas toleransi kandungan lumpur. Pemeriksaan berat jenis, kadar air, penyerapan dan berat isi pasir Palu disajikan pada tabel 3 berikut.

Tabel 3. Hasil Pemeriksaan Pasir Palu

\begin{tabular}{llcc}
\hline No & $\begin{array}{l}\text { Jenis } \\
\text { Pemeriksaan }\end{array}$ & Satuan & $\begin{array}{l}\text { Pasir } \\
\text { Palu }\end{array}$ \\
\hline 1 & Berat Jenis & - & 2.43 \\
& SSD & $\%$ & 4,21 \\
2 & Kadar Air & $\%$ & 2,88 \\
3 & Penyerapan & gram $/ \mathrm{m}^{3}$ & 1.44 \\
4 & Berat Isi & & \\
\hline
\end{tabular}

Berdasarkan Tabel 3, diperoleh nilai kadar air sebesar 4,21 pada kondisi pasir dilapangan, sehingga perlu dilakukan koreksi pada perhitungan mix design.

Pemeriksaan Agregat Kasar Nilai MHB untuk agregat kasar adalah 5,0 8,0 . Berdasarkah hasil pengujian kerikil palu diperoleh nilai MHB sebesar 5,12 ini menunjukkan MHB kerikil palu telah sesua dengan nilai MHB untuk agregat kasar. Dari pemeriksaan kadar lumpur yang terkandung dalam kerikil terdapat kandungan lumpur didalam kerikil Palu sebesar 2,41\% kadar lumpur. Berdasrakan Perturan Beton Indonesia (PBI) 1971 kandungan maksimal kadar lumpur pada agregat ksar adalah sebesar $1 \%$.
Berdasarkan hal tersebut maka pada saat akan kerikil Palu akan disunakan untuk pencampuran beton, agregat harus dicuci terlebih dahulu. Pemeriksaan berat jenis, kadar air, penyerapan dan berat isi kerikil Palu disajikan pada tabel 4. berikut.

Tabel 3. Hasil Pemeriksaan Kerikil Palu

\begin{tabular}{llcl}
\hline No & $\begin{array}{l}\text { Jenis } \\
\text { Pemeriksaan }\end{array}$ & Satuan & $\begin{array}{l}\text { Kerikil } \\
\text { Palu }\end{array}$ \\
\hline 1 & Berat Jenis & - & 2.36 \\
2 & SSD & $\%$ & 1,36 \\
3 & Kadar Air & $\%$ & 1,5 \\
4 & Penyerapan & gram $/ \mathrm{m}^{3}$ & 1.68 \\
\hline
\end{tabular}

Berdasarkan Tabel 4, kerikil Palu memiliki kadar air yang rendah dibandingkan dengan kadar air pada pada pasir Palu.

\subsection{Pemeriksaan Batu Laterit}

Pada penelitian ini batu laterit yang akan digunakan dipecahkan sedemikian rupa agar memiliki ukuran maksimum yang menyerupai kerikil Palu yang digunakan yaitu sebesar $20 \mathrm{~mm}$. Dari pemeriksaan modulus halus butir (MHB) batu laterit diperoleh nilai nilai MHB yaitu sebesar 5,42. Hasil ini memenuhi syarat karena berada dalam nilai $\mathrm{MHB}$ pasir yaitu 5,0 - 8,0.

Dari pemeriksaan kadar lumpur yang terkandung dalam kerikil terdapat kandungan lumpur didalam kerikil Palu sebesar $0,74 \%$ Pemeriksaan berat jenis, kadar air, penyerapan dan berat isi batu laterit disajikan pada tabel 5 berikut.

Tabel 5. Hasil Pemeriksaan Pasir Palu

\begin{tabular}{clcl}
\hline No & $\begin{array}{l}\text { Jenis } \\
\text { Pemeriksaan }\end{array}$ & Satuan & $\begin{array}{l}\text { Batu } \\
\text { Laterit }\end{array}$ \\
\hline 1 & $\begin{array}{l}\text { Berat Jenis } \\
\text { SSD }\end{array}$ & - & 1.82 \\
2 & Kadar Air & $\%$ & 0.15 \\
3 & Penyerapan & $\%$ & 0.5 \\
4 & Berat Isi & gram $/ \mathrm{m}^{3}$ & 0.633 \\
\hline
\end{tabular}




\section{DynamicSainT}

Jilid. IV No. 2., Oktober 2019

Dari Tabel 5 diperoleh nilai berat jenis batu laterit yang lebih kecil dari berat jenis kerikil, nilai ini menunjukkan bahwa batu laterit lebih ringan dibandingkan kerikil Palu.

\subsection{Pengujian Slump}

Untuk mengetahui kelecakan (consistency) adukan beton segar maka dilakukan pengujian slump yang akan menunjukkan tingkat kelecakan adukan yang berpengaruh terhadap sifat mudah dikerjakan. Nilai slump dapat dilihat pada Tabel.6 berikut ini

Tabel 6. Hasil Pengujian Slump Beton Segar

\begin{tabular}{ccc}
\hline No & Kode Variasi & Nilai Slump \\
\hline 1 & BN & 14,5 \\
2 & LT1 & 14,3 \\
3 & LT2 & 14,3 \\
4 & LT3 & 14,1 \\
5 & LT4 & 14,3 \\
6 & LT5 & 14,3 \\
\hline
\end{tabular}

Hasil pengujian slump dapat juga digambarkan seperti pada Gambar 1. dibawah ini.

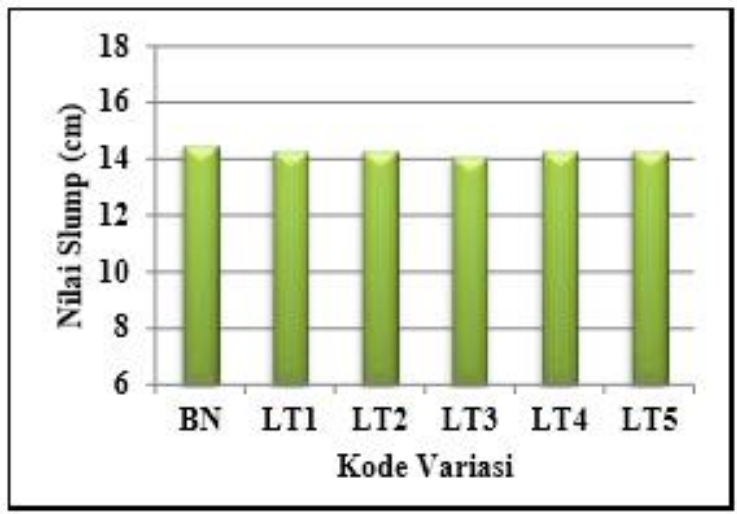

Gambar 1. Nilai Slump Beton

Berdasarkan Tabel 6 dan Gambar 1 dapat disimpulkan bahwa nilai slump yang diperoleh sesuai dengan nilai slump yang direncanakan pada mix design yaitu antara $6-18 \mathrm{~cm}$, sehingga sifat mudah dikerjakan dari adukan beton telah tercapai. Dari hasil pengujian slump tersebut juga dapat disimpulkan bahwa nilai slump antara beton normal (BN) dan beton variasi (LT) tidak berselisih banyak, ini dikarenakan daya serap batu laterit yang sangat rendah dibandingkan kerikil Palu. Secara umum nilai slump telah masukdalam persaratan pada PBI 1971.

\subsection{Pengujian Berat Isi Beton}

Pengujian berat isi beton berfungsi untuk menentukan salah satu sifat karakteristik beton yaitu berat volume isi. Hasil pengujian berat isi beton dapat dilihat pada Gambar 2.

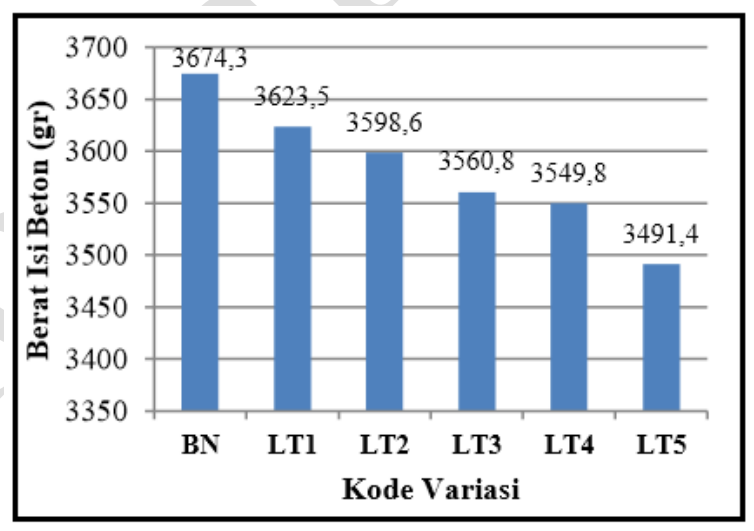

Gambar 1. Berat Isi Beton

Berdasarkan Gambar 2 dapat disimpulkan bahwa semakin banyak persentase penggunaan batu laterit pada campuran beton maka berat isi beton semakin berkurang, hal ini disebabkan oleh berat jenis batu laterit lebih kecil atau lebih ringan dibandingkan dengan berat jenis dari kerikil Palu.

\subsection{Pengujian Kuat Tekan Beton}

Pengujian kuat tekan beton tercantum pada Tabel 7 berikut ini

Tabel 7. Hasil Pengujian Kuat Tekan Beton

\begin{tabular}{ccc}
\hline No & Kode Variasi & $\begin{array}{c}\text { Kuat Tekan } \\
\text { Rat-rata } \\
(\mathrm{MPa})\end{array}$ \\
\hline 1 & BN & 25,8 \\
2 & LT1 & 25,1
\end{tabular}




\section{DynamicSainT}

Jilid. IV No. 2., Oktober 2019

\begin{tabular}{llc}
3 & LT2 & 16,9 \\
4 & LT3 & 12,4 \\
5 & LT4 & 11,5 \\
6 & LT5 & 8,9 \\
\hline
\end{tabular}

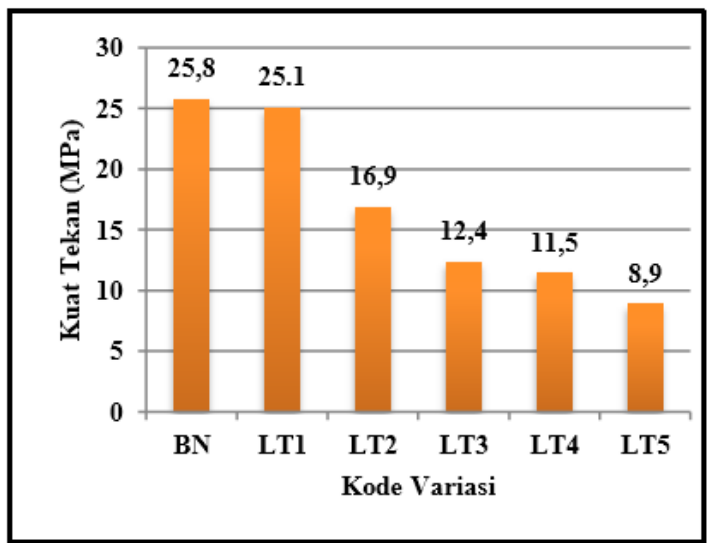

Gambar 3. Kuat Tekan Rata-rata Beton

Dari Tabel 7 dan Gambar 3 dapat dijabarkan sebagai berikut, beton yang menggunakan $100 \%$ kerikil Palu (BN) memiliki kuat tekan rata-rata sebesar 25,8 MPa, beton variasi LT1 memperoleh kuat tekan rata-rata sebesar $25,1 \mathrm{MPa}$, beton variasi LT2 memperoleh kuat tekan rata-rata sebesar 16,9 $\mathrm{MPa}$, beton variasi LT3 memperoleh kuat tekan rata-rata sebesar 12,4 $\mathrm{MPa}$, beton variasi LT4 memperoleh kuat tekan rata-rata sebesar 11,5 MPa dan beton variasi LT5 memperoleh kuat tekan rata-rata sebesar 8,9 MPa Dari hasil pengujian tersebut dapat disimpulkan bahwa semakin besar presentase penggunaan batu laterit maka semakin kecil kuat tekan beton yang diperoleh, hal ini disebabkan oleh kekuatan kerikil Palu lebih besar dari kekuatan batu laterit. Dari pengujian ini menujukkan batu laterit dapat digunakan sebagai alternatif pengganti parsial agregat kasar dengan presentae penggunaan $10 \%$ dari kerikil Palu dikarenakan pada presantase tersebut kekuatan beton mencapai kekuatan yang direncakan yaitu sebesar $25 \mathrm{MPa}$ dan juga pada persentase tersebut kekuatan tariknya mendekati beton yang menggunakan 100\% kerikil Palu sebagai agregat kasar.

\section{KESIMPULAN DAN SARAN}

\subsection{Kesimpulan}

Berdasarkan data yang diperoleh dari hasil pengujian beton normal (BN) dengan 5 variasi sampel (LT) dapat disimpulkan sebagai berikut.

Dari pengujian kuat tekan beton variasi diperoleh kuat tekan rata-rata sebagai berikut LT1 memperoleh kuat tekan rata-rata sebesar 25,1 MPa, beton variasi LT2 memperoleh kuat tekan rata-rata sebesar $16,9 \mathrm{MPa}$, beton variasi LT3 memperoleh kuat tekan rata-rata sebesar 12,4 $\mathrm{MPa}$, beton variasi LT4 memperoleh kuat tekan rata-rata sebesar 11,5 MPa dan beton variasi LT5 memperoleh kuat tekan rata-rata sebesar 8,9 MPa.

Beton dengan variasi penggunaan batu laterit $10 \%$ (LT1) memiliki kuat tekan yang paling optimal sebesar 25,1 MPa diamana nilai tersebut mendekati nilai kuat beton normal (BN) sebesar 25,8 Mpa.

\subsection{Saran}

Untuk penelitian selanjutnya dapat digunakan batu laterit dari daerah lain dan juga perlu diuji penggunaan batu laterit pada variasi dibawah $10 \%$.

\section{DAFTAR PUSTAKA}

5. Amal, A.S., dan Saleh, C. 2015, "Pemanfaataan Limbah Batu Marmer Sebagai Pengganti Agregat Kasar pada Campuran Aspal Beton Terhadap Karakteristik Marshall", Media Teknik Sipil Volume 13, Nomor 2 (hlm.117126). Universitas Muhammadiyah Malang.

6. Angelina, E.L., 2013, "Potensi Batu Bauksit Pulau Bintan Sebagai Pengganti Agregat Kasar Pada Beton", JTS, Volume 12, No. 3 (hlm.155-160). Universitas Atmajaya Yogyakarta

7. Ashdi, P.,Yudi, P., dan M. Ika., P. 2018, "Penambahan Batu Laterit Sebagai Bahan Substitusi Agregat Kasar pada Perkerasan 
Asphalt Concerete-Binder Course (ACBC)", Prosiding SNITTPoliteknik Negeri Balikpapan (hlm. 212-218). Politeknik Negeri Balikpapan

8. Karmila, A. 2015, “ Pasir Kandilo dan Kerikil Petangis Sebagai Material Local Tanah Grogot dalam Campuran Beton", Media Teknik Sipil Volume 13, Nomor 2 (hlm.157-160). Universitas Muhammadiyah Malang.

9. Mulyono, T. 2003, Teknologi Beton, Penerbit Andi, Yogyakarta

10.PBI 1971-NI-2, Peraturan Beton Indonesia, Direktorat Penyelesaian Masalah Bangunan.

11.SNI-03-2834-2000, Tata Cara Pembuatan Rencana Campuran Beton Normal.

12.SNI 03-2816-1992, Metode Pengujian Kotoran Organik dalam Pasir untuk Campuran Mortar atau Beton.

13.Tjokrodimuljo, K. 1992, Teknologi Beton, Fakults Teknik Universitas Gadjah Mada, Yogyakarta. 